\title{
Do contrasting patterns of migration movements and disease outbreaks between congeneric waterfowl species reflect differing immunity?
}

\author{
Shenglai Yin, ${ }^{1,2}$ Yanjie Xu, ${ }^{2,3}$ Nyambyar Batbayar, ${ }^{4}$ John Y. Takekawa, ${ }^{5}$ Yali Si,,${ }^{6,7}$ \\ Diann J. Prosser, ${ }^{8}$ Scott H. Newman, ${ }^{9}$ Herbert H.T. Prins, ${ }^{2,10}$ Willem F. de Boer $^{2}$ \\ ${ }^{1}$ College of Life Science, Nanjing Normal University, Nanjing, China; ${ }^{2}$ Wildlife Ecology and Conservation \\ Group, Wageningen University, Wageningen, The Netherlands; ${ }^{3}$ The Finnish Museum of Natural History, \\ University of Helsinki, Helsinki, Finland; ${ }^{4}$ Wildlife Science Conservation Centre of Mongolia, Ulaanbaatar, \\ Mongolia; ${ }^{5}$ Suisun Resource Conservation District, Suisun City, CA, USA; ${ }^{6}$ Ministry of Education Key \\ Laboratory for Earth System Modelling and Department of Earth System Science, Tsinghua University, \\ Beijing, China; ${ }^{7}$ Institute of Environmental Sciences, Leiden University, Leiden, The Netherlands; \\ ${ }^{8}$ U.S. Geological Survey, Patuxent Wildlife Research Centre, Laurel, MD, USA; ${ }^{9}$ Food and Agriculture \\ Organization of the United Nations, Regional Office for Africa, Accra, Ghana; ${ }^{10}$ Department of Animal \\ Sciences, Wageningen University, Wageningen, The Netherlands
}

\begin{abstract}
Correspondence: Willem F. de Boer, Wildlife Ecology and Conservation Group, Wageningen University, 6708PB Wageningen, The Netherlands.

Tel.: +31.31.7482.691 - Fax: +31.31.7485.828.

E-mail: fred.deboer@wur.nl

Key words: Avian influenza; Bar-headed goose; Swan goose; Migration.

Acknowledgements: We thank contributions of all partners in the USGS-FAO studies and Tsinghua University for their efforts in field work. We thank Jerry Hupp and Tetsuo Shimada for their efforts in tracking wild Whooper swan. We also thank Kevin Matson, Weixuan Peng, Wenyuan Zhang, and Fei Xu for their inspiring discussions and Olivia Hughes and Jeffery Sullivan for improving earlier versions of this manuscript. The use of trade, product, or firm names in this publication is for descriptive purposes only and does not imply endorsement be the U.S. Government. The views expressed in this information product are those of the author(s) alone and do not necessarily reflect the views or policies of FAO.
\end{abstract}

Funding: This work was supported by the Ph.D. scholarship to Shenglai Yin from the Chinese Scholarship Council (grant numbers 201406190178) and the National Natural Science Foundation of China (grant numbers 41471347).

Contributions: SY and YX equally contributed to this manuscript. SY, YX, JYT, WFdB and HHTP conceived, coordinated this study; SY and YX carried out the analysis and drafted the manuscript; NB, JYT, YS, DJP and SHN collected the filed data; all authors critically revised the manuscript, gave final approval for publication and agree to be held accountable for the work performed therein.

Received for publication: 22 June 2020.

Revision received: 17 September 2020.

Accepted for publication: 17 September 2020.

(c) Copyright: the Author(s), 2021

Licensee PAGEPress, Italy

Geospatial Health 2021; 16:909

doi:10.4081/gh.2021.909

This article is distributed under the terms of the Creative Commons Attribution Noncommercial License (CC BY-NC 4.0) which permits any noncommercial use, distribution, and reproduction in any medium, provided the original author(s) and source are credited.

\begin{abstract}
Long-distance migrations influence the dynamics of hostpathogen interactions and understanding the role of migratory waterfowl in the spread of the highly pathogenic avian influenza viruses (HPAIV) is important. While wild geese have been associated with outbreak events, disease ecology of closely related species has not been studied to the same extent. The swan goose (Anser cygnoides) and the bar-headed goose (Anser indicus) are congeneric species with distinctly different HPAIV infection records; the former with few and the latter with numerous records. We compared movements of these species, as well as the more distantly related whooper swan (Cygnus cygnus) through their annual migratory cycle to better understand exposure to HPAIV events and how this compares within and between congeneric and noncongeneric species. In spite of their record of fewer infections, swan geese were more likely to come in contact with disease outbreaks than bar-headed geese. We propose two possible explanations: i) frequent prolonged contact with domestic ducks increases innate immunity in swan geese, and/or ii) the stress of high-elevation migration reduces immunity of bar-headed geese. Continued efforts to improve our understanding of species-level pathogen response is critical to assessing disease transmission risk.
\end{abstract}

\section{Introduction}

Long-distance migrations in wildlife co-determine the dynamics of host-pathogen interactions (Altizer et al., 2011). The role migration plays in the host-pathogen relationship can be extremely complex, with migration presenting an opportunity for a disease to spread across a landscape while also potentially reducing prevalence via death during travel or allowing healthy individuals to separate from infected individuals or regions (Altizer et al., 2011; Risely et al., 2018). Migration can even be an important part in the life cycle of a pathogen due to reduced immune function (Owen \& Moore, 2008; Hawley \& Altizer, 2011) and increased exposure of the host across the migratory route (Fritzsche \& Hoye, 2016; Leung \& Koprivnikar, 2016), or by animals being together in dense congregations thereby facilitating disease transmission (Hill 
et al., 2012; Fritzsche \& Hoye, 2016; van Dijk et al., 2018). However, despite the complex and compelling relationship between wildlife migrations and the potential pathogens these animals carry, relatively few studies have examined how annual migration movements affect the transmission and evolution of pathogens within host populations (Hall et al., 2014; Verhagen et al., 2015). A prime example of this dearth of information is found in wild waterfowl whose migration is a well-known ecological phenomenon; yet, the relationship between migration and disease spread is not well understood.

Traditional amplification routes of avian influenza viruses include direct or indirect transmission of the non-lethal, lowpathogenic avian influenza virus (LPAIV) from wild bird reservoirs to highly-dense populations such as farmed poultry. This transmission is often facilitated by agricultural practices with low biosecurity (Takekawa et al., 2010a and b; Fearnley, 2015), such as grazing domestic ducks in marshes where they can comingle with migratory wild birds. This viral flow is demonstrated by the amplified infection prevalence of locally circulating LPAIVs observed concurrent with the arrival of migratory waterfowl (Lisovski et al., 2018; Verhagen et al., 2015). Once introduced to highly concentrated poultry herds in domestic facilities, LPAIVs can easily mutate into a highly pathogenic virus, which can have dramatic impacts on affected poultry farms (Wallace, 2016).

The emergence of the Asian lineage HPAI H5N1 virus marked the evolution of the highly pathogenic avian influenza viruses (HPAIV) spill-over from poultry to wild birds and the environment. For instance, the HPAIV H5N1 outbreak at Qinghai Lake in 2005 killed over 6000 wild migratory waterfowl, more than $90 \%$ of which were bar-headed geese (Anser indicus) (Chen et al., 2005; Liu et al., 2005). Subsequent research has suggested that, much like the introduction of LPAIV from wild birds to domestic poultry, spill-over of HPAIV from domestic poultry to wild birds is likely facilitated by agricultural practices (Hénaux \& Samuel, 2011; Prosser et al., 2016; Stallknecht et al., 1990) that enable co-occurrence of the virus and its avian hosts in wetlands (Prosser et al., 2016; Takekawa et al., 2010a). Thus, areas with high concentrations of domestic ducks and geese as well as migratory waterfowl, such as southeast China (Prosser et al., 2013), are especially prone to outbreaks of HPAIV and can serve as disease hotspots (Gilbert et al., 2012; Cappelle et al., 2014). However, once HPAIV spillover into the environment, it is not limited to these high-risk areas. Research indicates that some waterfowl species can migrate while infected with HPAIV (Hill et al., 2012), which strengthen the potential for long-distance dispersal (Altizer et al., 2011; Verhagen et al., 2015).

Though previous work has addressed many questions regarding the spatial-temporal correlations between waterfowl migration and HPAIV outbreaks (Newman et al., 2009; Si et al., 2009; Verhagen et al., 2014), phylogenetic relationships among outbreaks (Tian et al., 2015; Xu et al., 2016), and outbreak drivers (Gilbert et al., 2007; Prosser et al., 2013), there are no studies we are aware of comparing HPAIV outbreak patterns in congeneric migratory waterfowl species. The swan goose (Anser cygnoides) and the bar-headed goose provide an ideal opportunity for examining avian influenza in congeners as these species both breed in Mongolia (Batbayar et al., 2013) and co-occur in some areas but follow separate migration routes (Batbayar, 2013). During the autumn migration, swan geese use northeast China and the Yalu River Estuary as important stopover sites (Batbayar et al., 2013) on their way to over-wintering in the Yangtze River lowlands via the East Asian-Australasian Flyway. In contrast, the bar-headed geese stopover at Qinghai Lake and wetlands on the Qinghai Plateau in the Central Asian Flyway (Takekawa et al., 2017) before migrating to southern Tibet or India. Additionally, while passive and active surveillance indicate that swan geese are generally infected infrequently and in low numbers (Kou et al., 2009; Welte \& Terán, 2004), bar-headed geese have been regularly documented in HPAIV outbreaks from 2004-2017. This suggests species differences, either with respect to exposure to, or immunity against, HPAIV (Welte \& Terán, 2004; Chen et al., 2005; Takekawa et al., Takekawa et al., 2010b). In this study, we compare migratory movements of the bar-headed geese and the swan geese and examine HPAIV outbreak patterns along their migration routes. We also contrast their movements to those of two whooper swan (Cygnus cygnus) populations to: i) provide comparison with a different genus of waterfowl that migrates along comparable habitats; and ii) examine whether HPAIV outbreak patterns between and within waterfowl species are correlated with the variable densities of domestic ducks. We discuss mechanisms that may contribute to differences in outbreak patterns and transmission, such as migration strategies and immunity.

\section{Materials and methods}

\section{Tracking data}

We obtained global positioning system (GPS) data tracking bar-headed geese and swan geese from the U.S. Geological Survey (USGS) and the Food and Agriculture Organization of the United Nations (FAO). In addition, we acquired data and for swan geese from the Department of Earth System Science at Tsinghua University, Beijing, China and included movement data of two whooper swan populations: one migrating between Mongolia and South Korea (USGS-FAO) and the other between Russia and Japan (Shimada et al., 2014). These different migration corridors overlap with high and low poultry density areas, respectively, which enables within-species comparison.

The USGS-FAO information included a total of 18 swan geese, 38 bar-headed geese, and 10 whooper swans captured in overwintering and breeding areas (Table 1); the Tsinghua University sample 44 swan geese marked in overwintering and breeding areas $(\mathrm{Xu}$ et al., 2016); and the Shimada et al. (2014) data concerned a total of 47 whooper swans captured in eastern Hokkaido and north-eastern Honku, Japan. The GPS and ARGOS platform transmitting terminals (see Table 1 for further information) were programmed to record locations at 2-hour intervals for swan geese and whooper swans and at 4-hour intervals for bar-headed geese. Additional information can be found in the Table 1 and in previous papers (Newman et al., 2009, 2012; Batbayar et al., 2013; Shimada et al., 2014; Xu \& Si, 2019; Xu et al., 2019).

\section{Migration route estimations}

We used dynamic Brownian Bridge Movement Models (dBBMM) to measure utilization distributions (UD) of the tracked populations (Kranstauber et al., 2012). The dBBMM assumes heterogeneous GPS tracks and thereby estimates UD with a sliding window of GPS locations for detecting behavioural changes. We used a resolution of $10 \mathrm{~km}$ with a sliding window encompassing 23 locations with a margin of 11 locations and a location error of 23 
$\mathrm{m}$ (Palm et al., 2015). We set the time step at 8 locations for swan geese and whooper swans and at 4 locations for bar-headed geese covering a 16-h period.

Because tracking durations varied among individuals, we weighted their individual UD by multiplying all raster values by the number of tracking days. Population-level UDs were calculated from the sum of weighed individual UDs, and we generated $90 \%$ cumulative probability contours to circumscribe their main use areas including breeding, stopover, and wintering areas (Si et al., 2018; Xu et al., 2019). We used 99\% cumulative probability contours to represent migration routes (Palm et al., 2015).

Because original tracking data for the Russia-Japan whooper swans were not available, we extracted coordinates for the main areas of wintering, stopover, and breeding sites from published maps (Shimada et al., 2014) via geo-referencing and created buffer zones around each of these geo-referenced sites with a radius of $32.5 \mathrm{~km}$, i.e. an average maximum foraging distance for waterfowl (Johnson et al., 2014).

\section{Poultry density measurements}

We obtained densities of domestic ducks from the Livestock Geo-Wiki (https://livestock.geo-wiki.org/home-2/). To evaluate the differences among migratory populations and their contact probability with poultry, we summarized densities of domestic ducks and chickens from each raster cell in sites used along their migration routes, derived from tracking data from 2004-2017. Differences in poultry densities in areas of different migratory populations were tested with Bonferroni corrected post-hoc tests (Dunn, 1961).

\section{Highly pathogenic avian influenza viruses outbreak assessments}

We obtained confirmed HPAIV outbreaks from 2004-2017 through EMPRES-i (Welte \& Terán, 2004). We assumed an outbreak window of 30 days (i.e., where the outbreak observation date is the median date) during which the virus may be transmitted to wild migratory birds that visit the outbreak areas with an incuba- tion period of 21 days plus a disinfection period of 9 days (Si et al., 2009). We extracted GPS locations for tracked individuals during each outbreak window and examined the distribution of distances between these locations and HPAIV outbreaks. Differences among cumulative distributions were tested with a Kolmogorov-Smirnov test (Frank \& Massey, 1951). We ran the analysis in R 3.4.3 (R Development Core Team, 2016) and QGIS 2.18 (QGIS Development Team, 2015).

\section{Results}

The marked swan geese bred in north-eastern Mongolia used the Yalu River Estuary at the border of China and North Korea as a stopover site and overwintered in the Yangtze River Lowlands of southern China including Poyang Lake. Bar-headed geese bred in north-western Mongolia and migrated over the Gobi Desert and the Qinghai-Tibetan Plateau. Eight of the 36 bar-headed geese crossed the Himalayas and overwintered in India, whereas the rest of the marked bar-headed geese overwintered near Lhasa, China. The breeding grounds for the population of whooper swans marked by the USGS-FAO were near the Mongolia-Russia border and they migrated to southern South Korea for overwintering. The other whooper swan population was located in north-eastern Russia and southern Japan (Figure 1).

There were no HPAIV outbreaks concerning swan geese in the EMPRES-i database between 2004 and 2017, but 11 HPAIV outbreaks in bar-headed geese and 37 in whooper swans (Table 2). The HPAIV outbreaks in bar-headed geese occurred in Mongolia, around Qinghai Lake, and in the Lhasa River Valley, while HPAIV outbreaks in whooper swans mainly occurred in Japan (Figure 1C).

There were fewer HPAIV outbreaks, i.e. outbreaks in domestic and wild birds along the migration route for swan geese compared with the other species. A total of 20 HPAIV outbreaks occurred along the migratory route of the swan geese, whereas 48 outbreaks occurred along the migration route of the bar-headed geese (Table 2). 67 outbreaks occurred along the migratory route of the whooper

Table 1. Summary of marked bird population data.

\begin{tabular}{|c|c|c|c|c|c|c|}
\hline $\begin{array}{l}\text { Population } \\
\text { of individuals }\end{array}$ & $\begin{array}{c}\text { Number } \\
\text { duration (days) }\end{array}$ & $\begin{array}{l}\text { Tracking } \\
\text { capture }\end{array}$ & Year of data & Capture location & GPS transmitter & Data source \\
\hline $\begin{array}{l}\text { Swan goose } \\
\text { Anser cygnoides }\end{array}$ & 18 & 1211 & 2006,2008 & $\begin{array}{l}\text { Khaichiin Tsagaan Lake, } \\
\text { Khorin Tsagaan Lake } \\
\text { and Khokh Lake, Mongolia }\end{array}$ & $\begin{array}{l}\text { Solar-powered Argos-GPS } \\
\text { platform transmitter terminals* }\end{array}$ & USGS/FAO \\
\hline $\begin{array}{l}\text { Swan goose } \\
\text { Anser cygnoides }\end{array}$ & 44 & 435 & 2015,2016 & Hulun Lake, China & GPS-GSM solar-powered loggers ${ }^{\circ}$ & Tsinghua University \\
\hline $\begin{array}{l}\text { Whooper swan } \\
\text { Cygnus cygnus }\end{array}$ & 10 & 820 & 2006 & $\begin{array}{l}\text { Khorin Tsagaan Nuur and Delger } \\
\text { Tsagaan Lake, Mongolia }\end{array}$ & $\begin{array}{l}\text { Solar-powered Argos-GPS } \\
\text { platform transmitter terminals* }\end{array}$ & USGS/FAO \\
\hline $\begin{array}{l}\text { Whooper swan } \\
\text { Cygnus cygnus }\end{array}$ & 47 & 1380 & 2009,2010 & $\begin{array}{l}\text { Lake Kussharo, } \\
\text { Lake Izunuma-Uchinuma }\end{array}$ & $\begin{array}{l}\text { Solar- and battery-powered } \\
\text { Argos-GPS platform transmitter } \\
\text { terminals* }\end{array}$ & Shimada et al. (2014) \\
\hline $\begin{array}{l}\text { Bar-headed goose } \\
\text { Anser indicus }\end{array}$ & 38 & 788 & 2008,2009 & $\begin{array}{l}\text { Terkhiin Tsagaan Lake, Mongolia, } \\
\text { Chilika Lake, East India, } \\
\text { Koonthankulum Bird Sanctuary, } \\
\text { South India }\end{array}$ & $\begin{array}{l}\text { Solar-powered Argos-GPS platform } \\
\text { transmitter terminals* }\end{array}$ & USGS/FAO \\
\hline
\end{tabular}

*Platform transmitting terminals: Microwave Telemetry, Inc., Columbia, MD, USA; ${ }^{\circ} \mathrm{GPS}-\mathrm{GSM}$, Global Positioning System - Global System for Mobile Communications. The transmitters were IBIS series, Ecotone Telemetry, Gdynia, Poland and necked HQNG series, Hunan Global Messenger Technology Co. Ltd., Xiangtan, China; The GPS and ARGOS transmitters were programmed to record GPS locations at 2-hour intervals for swan geese and whooper swans and 4-hour intervals for bar-headed geese. 
Swans from Mongolia, and 44 outbreaks occurred in the sites of whooper swans in Russia and Japan (Table 2).

Swan geese were closer to outbreak locations than bar-headed geese and whooper swans within a radius of $500 \mathrm{~km}$ around outbreak events (Figure 2D). Densities of domestic ducks in both the stopover, breeding and wintering sites and migration routes of the swan geese were also higher than those for bar-headed geese (Figure 2A and B). Densities of domestic ducks in the 90\% cumulative probability contours of the Mongolia-South Korean whooper swan population was higher compared to those in Russia and Japan (Figure 2C), but the number of outbreaks was higher for the Russia-Japan population (Table 2).

\section{Discussion and conclusions}

We compared HPAIV outbreak patterns between two congeneric species, the swan geese and the bar-headed geese and found that there were no recorded HPAIV outbreaks in the former but multiple outbreaks in latter. Contrary to our expectations, swan geese were found closer to outbreak areas than bar-headed geese during HPAIV outbreaks. Also, areas used by swan geese had significantly higher duck densities than areas used by bar-headed geese that were often reported in outbreaks. Although the swan geese were more likely to be present in HPAIV outbreak areas during migration, they had a lower chance of being infected with

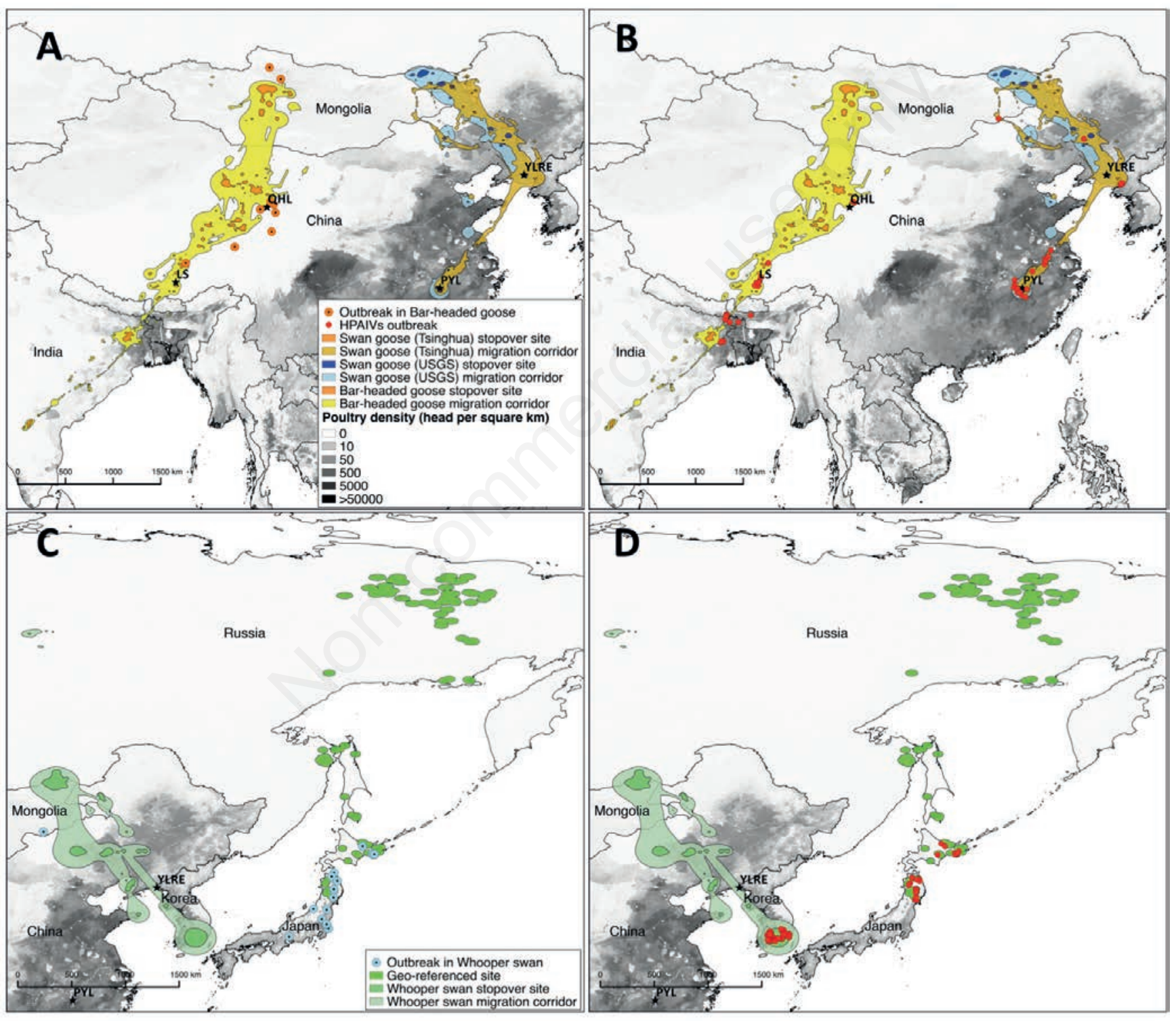

Figure 1. Primary stopover sites, migration corridors for bar-headed geese and swan geese. The swan geese are from different marked populations (A and B) overlaid on poultry densities (grey shading) where darker shades indicate higher densities. For comparison, relationship of domestic poultry densities with two whooper swan populations are shown (C and D). Black stars represent important stopover sites for the migratory geese, including Qinghai Lake (QHL), Yalu River Estuary (YLRE), Poyang Lake (PYL), and Lhasa region (LS). Orange circles represent HPAIV outbreaks in bar-headed geese. Blue circles represent HPAIV outbreaks in whooper swans. Red dots are the confirmed HPAIVs outbreaks in wild birds and domestic birds. 
HPAIVs. However, the bar-headed geese were less likely to contact HPAIVs outbreaks during migration but had multiple HPAIV outbreaks. We postulate two possible explanations for this: i) frequent contact and long contact history with domestic ducks might cause greater levels of innate immunity in swan geese; and/or ii) the high elevation Himalayan migration of bar-headed geese could compromise their immunity resulting in greater vulnerability to HPAIV infection.

Firstly, wild birds that have frequent contacts with domestic birds are less often found in outbreaks because they may have greater levels of immunity from frequent exposure to poultry (Brown et al., 2008; Nemeth et al., 2013; Pantin-Jackwood et al.,
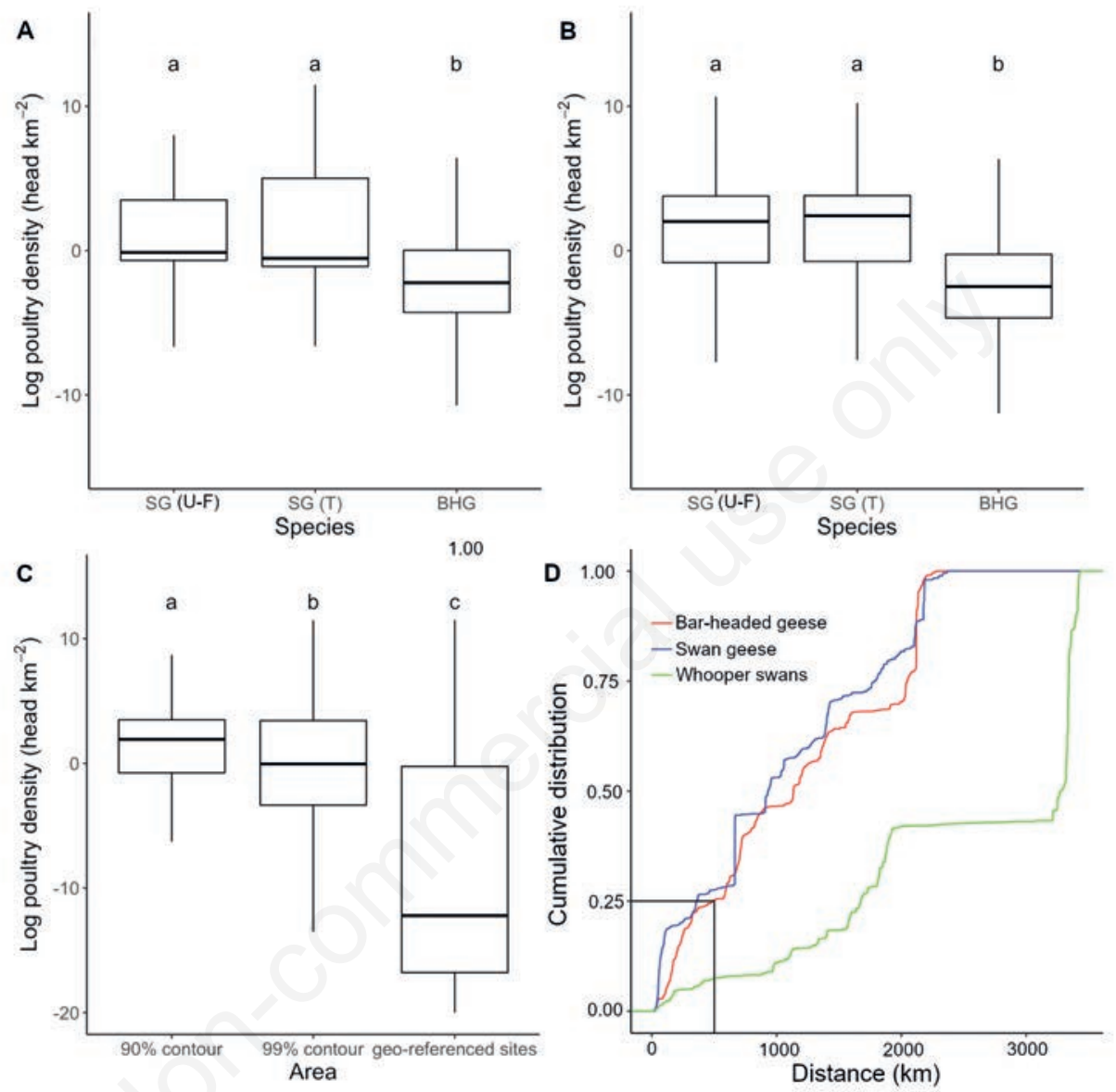

Figure 2. Density differences among domestic ducks in stopover sites for swan geese and bar-headed geese in their migration corridors compared to stopover sites and migration corridors for whooper swans. A) domestic ducks in stopover sites for swan geese (SG) and bar-headed geese (BHG); B) domestic ducks in migration corridors for swan geese and bar-headed geese; C) domestic ducks in stopover sites and migration corridors for Mongolia-South Korea population of whooper swans and geo-referenced sites for Russia-Korea population of whooper swans; D) cumulative density distribution of geographic distances of marked bar-headed geese from 2008 and 2009 combined (red), Swan geese from 2006-2017 combined (blue), whooper swans from 2008-2012 combined (green), respectively, and the total HPAIV outbreaks from 2004-2017. (a), (b) and (c) indicate significantly different groups on the basis of Bonferroni corrected post hoc tests. 'U-F' and ' $\mathrm{T}$ ' in (A) and (B) represent the population marked by USGS/FAO and Tsinghua University, respectively.

Table 2. Summary of outbreaks in different bird populations.

\begin{tabular}{lcc} 
Population & Outbreaks in the study populations & Outbreaks in other species* \\
Swan goose & 0 & 20 \\
Bar-headed goose & 11 & 48 \\
\hline Whooper swan (Mongolia-S. Korea) & 0 & 67 \\
Whooper swan (Russia-Japan) & 37 & 44
\end{tabular}

*In wild birds and poultry birds using the study species' migration corridor; the whooper swan populations were included to provide a comparison of one species with two different migration routes. 
2017). Migratory individuals have larger immunological organs than resident birds (Møller \& Erritzøe, 1998) due to frequent exposure to pathogens during migration (Brown et al., 2008). The whooper swan population that had a higher probability of contact with domestic ducks had no HPAIV outbreak records, whereas the whooper swan population that had a lower probability of contact with domestic ducks was associated with more HPAIV outbreaks (Figure 2). This is consistent with our findings for differences between swan geese and bar-headed geese, as birds with a higher probability of contacting poultry had fewer HPAIV outbreaks (Figure 2A and B; Table 2). Frequent contacts with domestic ducks may increase innate immunity responses in swan geese. We found that the densities of domestic ducks were significantly higher in the East Asian-Australasian Flyway, especially near Poyang Lake where 14 million domestic ducks are produced annually (Cappelle et al., 2014) with the ratio of domestic ducks to wild birds being around 5:1 (Takekawa et al., 2010b). Thus, the HPAIV transmission risk between swan geese and domestic ducks are substantially higher here (Wang et al., 2013; Cappelle et al., 2014). Furthermore, swan goose has a long contact history with domestic ducks in East Asia (Darwin, 1859; Niu, 2016), which might be a selective driver for higher levels of innate immunity (Møller \& Erritzøe, 1998). In addition, domestic swan goose is a common poultry species in this region, meaning that viruses circulating in domestic poultry may also be better adapted to this species and thereby counteract any enhanced immunity from increased exposure.

Secondly, although bar-headed geese are well-known victims of HPAIV outbreaks in the wild (Chen et al., 2005; Takekawa et al., 2010b), only 2 of 8 bar-headed geese died in experimental HPAI H5N1 infections (Brown et al., 2008; Nemeth et al., 2013). This mortality rate $(25 \%)$ is lower compared with other waterfowl species (Brown et al., 2008; Møller \& Erritzøe, 1998) indicating that, in non-migration conditions, bar-headed geese may be less vulnerable to HPAI H5N1 infection than other species. However, migrating over the Himalayas and the associated stress of long flight and scaling heights may decrease the immune responses of these geese. Migration is an energetically costly strategy, increasing the metabolic rate 10 times (Battley \& Piersma, 2005), a cost that has to be balanced against other expenses, such as immune responses (Altizer et al., 2011; van Dijk \& Matson, 2016). For example, migratory barn swallows (Hirundo rustica) (Johnson et al., 2014; Møller \& Erritzøe, 1998) and thrushes (Catharus spp and Hylocichla mustelina) (Owen \& Moore, 2006) have been found to be immunocompromised compared with non-migratory conspecific ones. The long-distance, high-altitude migration strategy of bar-headed geese is indeed energetically challenging (Hawkes et al., 2011). Some bar-headed goose populations migrate shorter distances between Qinghai Lake and Lhasa, but they need to allocate more energy to withstand the harsh Tibetan climate (Takekawa et al., 2017). Energetically costly migration at high altitudes suppresses immune the immune system (Bishop et al., 2015; van Dijk \& Matson, 2016) increasing the vulnerability of bar-headed geese to disease.

In light of these findings, we suggest that more comparative studies should be conducted to examine innate immunological differences among migratory waterfowl species, testing whether contact with domestic ducks stimulate the innate immune reactions against HPAIVs. Furthermore, we suggest physiological studies to investigate whether migration suppresses immune responses. These efforts can be helpful for understanding the HPAIV outbreak pattern and improving our understanding of pathogen dispersal via migratory hosts.

\section{References}

Altizer S, Bartel R, Han BA, 2011. Animal migration and infectious disease risk. Science 331:296-302.

Batbayar N, Takekawa JY, Newman SH, Prosser DJ, Natsagdorj T, Xiao X, 2013. Migration strategies of Swan Geese Anser cygnoides from northeast Mongolia. Wildfowl 61:90-109.

Batbayar N, 2013. Breeding and migration ecology of bar-headed goose Anser indicus and swan goose Anser cygnoides in Asia. University of Oklahoma.

Battley PF, Piersma T, 2005. Body composition and flight ranges of bar-tailed godwits (Limosa lapponica baueri) from New Zealand. The Auk 122:922-37.

Bishop CM, Spivey RJ, Hawkes LA, Batbayar N, Chua B, Frappell PB, Milsom WK, Natsagdorj T, Newman SH, Scott GR, 2015. The roller coaster flight strategy of bar-headed geese conserves energy during Himalayan migrations. Science 347:250-54.

Brown JD, Stallknecht DE, Swayne DE, 2008. Experimental infection of swans and geese with highly pathogenic avian influenza virus (H5N1) of Asian lineage. Emerg Infect Dis 14:136-42.

Cappelle J, Zhao D, Gilbert M, Nelson MI, Newman SH, Takekawa JY, Gaidet N, Prosser DJ, Liu Y, Li P, 2014. Risks of avian influenza transmission in areas of intensive free-ranging duck production with wild waterfowl. EcoHealth 11:109-19.

Chen H, Smith GJD, Zhang SY, Qin K, Wang J, Li KS, Webster R, Peiris J, Guan Y, 2005. Avian flu: H5N1 virus outbreak in migratory waterfowl. Nature 436:191-2.

Darwin C, 1859. On the origin of species by means of natural selection. Murray, London, UK, 502.

Dunn OJ, 1961. Multiple comparison among means. J Am Stat Assoc 56:52-64.

Fearnley L, 2015. Wild goose chase: The displacement of influen$\mathrm{za}$ research in the fields of Poyang Lake, China. Cult Anthropol 30:12-35.

Frank J, Massey JR, 1951. The Kolmogorov-Smirnov test for goodness of fit. J Am Stat Assoc 46:68-78.

Fritzsche MA, Hoye BJ, 2016. Are migratory animals superspreaders of infection? Integr Comp Biol 56:260-7.

Gilbert M, Jambal L, Karesh WB, Fine A, Shiilegdamba E, Dulam $\mathrm{P}$, Sodnomdarjaa R, Ganzorig K, Batchuluun D, Tseveenmyadag N, 2012. Highly pathogenic avian influenza virus among wild birds in Mongolia. PLoS One 7:e44097.

Gilbert M, Xiao X, Chaitaweesub P, Kalpravidh W, Premashthira S, Boles S, Slingenbergh J, 2007. Avian influenza, domestic ducks and rice agriculture in Thailand. Agr Ecosyst Environ 119:409-15.

Hall RJ, Altizer S, Bartel RA, 2014. Greater migratory propensity in hosts lowers pathogen transmission and impacts. J Anim Ecol 83:1068-77.

Hawley DM, Altizer SM, 2011. Disease ecology meets ecological immunology: understanding the links between organismal immunity and infection dynamics in natural populations. Funct Ecol 25:48-60.

Hawkes LA, Balachandran S, Batbayar N, Butler PJ, Frappell PB, Milsom WK, Tseveenmyadag N, Newman SH, Scott GR, Sathiyaselvam P, 2011. The trans-Himalayan flights of barheaded geese (Anser indicus). Proc Natl Acad Sci 108:9516-9. 
Hénaux V, Samuel MD, 2011. Avian influenza shedding patterns in waterfowl: implications for surveillance, environmental transmission, and disease spread. J Wild Dis 47:566-78.

Hill NJ, Takekawa JY, Ackerman JT, Hobson KA, Herring G, Cardona CJ, Runstadler JA, Boyce WM, 2012. Migration strategy affects avian influenza dynamics in mallards (Anas platyrhynchos). Mol Ecol 21:5986-99.

Johnson WP, Schmidt PM, Taylor DP, 2014. Foraging flight distances of wintering ducks and geese: a review. Avian Conserv Ecol 9:2.

Kou Z, Li Y, Yin Z, Guo S, Wang M, Gao X, Li P, Tang L, Jiang P, Luo Z, 2009. The survey of H5N1 flu virus in wild birds in 14 provinces of China from 2004 to 2007. PLoS One 4:e6926.

Kranstauber B, Kays R, Lapoint SD, Wikelski M, Safi K, 2012. A dynamic Brownian bridge movement model to estimate utilization distributions for heterogeneous animal movement. J Anim Ecol 81:738-46.

Leung TL, Koprivnikar J, 2016. Nematode parasite diversity in birds: the role of host ecology, life history and migration. J Anim Ecol 85:1471-80.

Lisovski S, van Dijk JGB, Klinkenberg D, Nolet BA, Fouchier RAM, Klaassen M, 2018. The roles of migratory and resident birds in local avian influenza infection dynamics. J Appl Ecol 55:2963-75.

Liu J, Xiao H, Lei F, Zhu Q, Qin K, Zhang XLW, Zhang X1, Zhao D, Wang G, Feng Y, 2005. Highly pathogenic H5N1 influenza virus infection in migratory birds. Science 309:1206.

Møller AP, Erritzøe J, 1998. Host immune defence and migration in birds. Evol Ecol 12: 945-953.

Newman SH, Iverson SA, Takekawa JY, Cappelle M, Prosser DJ, Batbayar N, Natsagdorj T, Douglas DC, 2009. Migration of whooper swans and outbreaks of highly pathogenic avian influenza H5N1 virus in eastern Asia. PLoS One 4:e5729.

Newman SH, Hill NJ, Spragens KA, Janies D, Voronkin IO, Prosser DJ, Yan B, Lei F, Batbayar N, Natsagdorj T, 2012. Ecovirological approach for assessing the role of wild birds in the spread of avian influenza H5N1 along the Central Asian Flyway. PLoS One 7:e30636.

Nemeth N, Brown JD, Stallknecht D, Howerth E, Newman S, Swayne D, 2013. Experimental infection of bar-headed geese (Anser indicus) and ruddy shelducks (Tadorna ferruginea) with a clade 2.3.2 H5N1 highly pathogenic avian influenza virus. Vet Pathol 50:961-70.

Niu Y, 2016. Traditional agriculture technique in China. Shantou University Press, Shantou, China.

Owen JC, Moore FR, 2006. Seasonal differences in immunological condition of three species of thrushes. Condor 108:389-98.

Owen JC, Moore FR, 2008. Swainson's thrushes in migratory disposition exhibit reduced immune function. J Ethol 26:383-8.

Pantin-Jackwood MJ, Costa-Hurtado M, Bertran K, DeJesus E, Smith D, Swayne DE, 2017. Infectivity, transmission and pathogenicity of $\mathrm{H} 5$ highly pathogenic avian influenza clade 2.3.4.4 (H5N8 and H5N2) United States index viruses in Pekin ducks and Chinese geese. Vet Res 48:33.

Palm EC, Newman SH, Prosser DJ, Xiao X, Ze L, Batbayar N, Balachandran S, Takekawa JY, 2015. Mapping migratory flyways in Asia using dynamic Brownian bridge movement models. Mov Ecol 3:3.

Prosser DJ, Hungerford LL, Erwin RM, Ottinger MA, Takekawa JY, Ellis EC, 2013. Mapping avian influenza transmission risk at the interface of domestic poultry and wild birds. Front
Public Heal 1:28.

Prosser DJ, Palm EC, Takekawa JY, Zhao D, Xiao X, Li P, Liu Y, Newman SH, 2016. Movement analysis of free-grazing domestic ducks in Poyang Lake, China: a disease connection. Int J Geogr Inf Sci 30:869-80.

QGIS Development Team, 2015. QGIS geographic information system. Open Source Geospatial Foundation Project.

R Development Core Team, 2016. R: A language and environment for statistical computing. R Found Stat Comput Vienna Austria.

Risely A, Klaassen M, Hoye BJ, 2018. Migratory animals feel the cost of getting sick: A meta-analysis across species. J Anim Ecol 87:301-14.

Shimada T, Yamaguchi NM, Hijikata N, Hiraoka E, Hupp JW, Flint PL, Tokita K, Fujita G, Uchida K, Sato F, Kurechi M, Pearce JM, Ramey AM, Higuchi H, 2014. Satellite tracking of migrating whooper swans Cygnus cygnus wintering in Japan. Ornithol Sci 13:67-75.

Si Y, Skidmore AK, Wang T, De Boer WF, Debba P, Toxopeus AG, Li L, Prins HHT, 2009. Spatio-temporal dynamics of global H5N1 outbreaks match bird migration patterns. Geospat Health 4:65-78.

Si Y, Xu Y, Xu F, Li X, Zhang W, Wielstra B, Wei J, Liu G, Luo H, Takekawa J, 2018. Spring migration patterns, habitat use, and stopover site protection status for two declining waterfowl species wintering in China as revealed by satellite tracking. Ecol Evol 8:6280-9.

Stallknecht D, Kearney M, Shane S, Zwank P, 1990. Effects of pH, temperature, and salinity on persistence of avian influenza viruses in water. Avian Dis 34:412-8.

Takekawa JY, Newman SH, Xiao X, Prosser DJ, Spragens KA, Palm EC, Yan B, Li T, Lei F, Zhao D, 2010a. Migration of waterfowl in the East Asian flyway and spatial relationship to HPAI H5N1 outbreaks. Avian Dis Dig 5:101-2.

Takekawa JY, Palm EC, Prosser DJ, Hawkes LA, Batbayar N, Balachandran S, Luo Z, Xiao X, Newman SH, 2017. Goose migration across the Himalayas: Migratory routes and movement patterns of bar-headed geese. Cambridge University Press, Cambridge, UK, pp. 15-29.

Takekawa JY, Prosser DJ, Newman SH, Muzaffar S Bin, Hill NJ, Yan B, Xiao X, Lei F, Li T, Schwarzbach SE, 2010b. Victims and vectors: highly pathogenic avian influenza H5N1 and the ecology of wild birds. Avian Biol Res 3:51-73.

Tian H, Zhou S, Dong L, Van Boeckel TP, Cui Y, Newman SH, Takekawa JY, Prosser DJ, Xiao X, Wu Y, 2015. Avian influenza H5N1 viral and bird migration networks in Asia. Proc Natl Acad Sci 112:172-7.

van Dijk JG, Matson KD, 2016. Ecological immunology through the lens of exercise immunology: new perspective on the links between physical activity and immune function and disease susceptibility in wild animals. Integr Comp Biol 56:290-303.

van Dijk JG, Verhagen JH, Wille M, Waldenström J, 2018. Host and virus ecology as determinants of influenza A virus transmission in wild birds. Curr Opin Virol 28:26-36.

Verhagen JH, Herfst S, Fouchier RA, 2015. How a virus travels the world. Science 347:616-7.

Verhagen JH, van Dijk JGB, Vuong O, Bestebroer T, Lexmond P, Klaassen M, Fouchier RA, 2014. Migratory birds reinforce local circulation of avian influenza viruses. PLoS One 9:e112366.

Wallace R, 2016. Big farms make big flu: dispatches on influenza, 
agribusiness, and the nature of science. NYU Press, NY, USA. Wang Y, Jiang Z, Jin Z, Tan H, Xu B, 2013. Risk factors for infectious diseases in backyard poultry farms in the Poyang Lake area, China. PLoS One 8:e67366.

Welte VR, Terán MV, 2004. Emergency prevention system (EMPRES) for transboundary animal and plant pests and diseases. The EMPRES-Livestock: An FAO initiative. Ann N Y Acad Sci 1026:19-31.

Xu F, Si Y, 2019 The frost wave hypothesis: How the environment drives autumn departure of migratory waterfowl. Ecol Indic 101:1018-25.

Xu Y, Gong P, Wielstra B, Si Y, 2016. Southward autumn migration of waterfowl facilitates cross-continental transmission of the highly pathogenic avian influenza H5N1 virus. Sci Rep 6:30262.

Xu Y, Si Y, Takekawa J, Liu Q, Prins HHT, Yin S, Prosser D, Gong P, de Boer WF, 2020. A network approach to prioritize conservation efforts for migratory birds. Conserv Biol 34:416-26. 